\title{
El boom minero en Colombia: ¿locomotora del desarrollo o de la resistencia?
}

\author{
Kyla SANkey
}

ReSumen. El boom minero de Colombia es un ejemplo claro de cómo los modelos de desarrollo neoliberales no surgen por su potencial para proporcionar «beneficios para todos», como pretenden sus partidarios, sino más bien como el resultado de la evolución de las relaciones de poder entre las clases dominantes y su interacción con la lucha de clases desde abajo, así como la influencia de las fuerzas del capital global y el imperialismo. Tras un análisis del proceso de reprimarización del modelo de desarrollo nacional desde una perspectiva crítica de la economía política, este trabajo examina las reconfiguraciones en las dinámicas de la lucha de clase generadas en los nuevos conflictos sociales que rodean el boom minero.

Palabras Clave: Colombia, minería, reprimarización de la economía, conflictos socioambientales, lucha de clases.

AвSt RACT. Colombiás mining boom provides a clear example of how neoliberal development models do not arise because of their potential to provide «benefits for all» but rather as a result of evolving power relations between the ruling classes and their interaction with the class struggle from below, as well as the influence of the forces of global capital and imperialism. Following an analysis of the emergence of the Colombian mining boom from a critical political-economy perspective, this article examines reconfigurations in the dynamics of class struggle generated by the new social conflicts around the mining boom. KEYwords: Colombia, mining, reprimarization of the economy, social-environmental conflicts, class struggle.

Kyla Sankey es estudiante del Doctorado de Estudios del Desarrollo de la Universidad Autónoma de Zacatecas, México. 


\section{INTRODUCCIÓN}

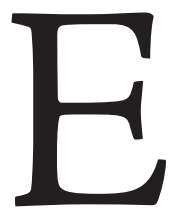

n la reserva de los indígenas Wayúu, El Provincial, en el Departamento de la Guajira, Colombia, lo que falta es agua. El río Ranchería, que ha proporcionado el suministro de agua de la comunidad durante siglos, ahora corre de un color opaco marrón rojizo (Orduz, 2012). Las 120 familias que dependen del río para su subsistencia sufren de diarrea y erupciones en la piel; la agricultura a pequeña escala y la pesca, que una vez sostuvo su medio de vida, han desaparecido (Рвi Colombia, 2011: 34). Todo esto comenzó hace 30 años, cuando un proyecto de minería de carbón a gran escala a cielo abierto empezó sus operaciones en la región. Hoy en día, la mina El Cerrejón, propiedad de un consorcio de la empresa australianabritánica Bнр Billiton, la corporación Británico Anglo American y la sociedad suiza Xstrata, es la mina carbonífera a cielo abierto más grande del mundo, con una producción diaria de 89 mil toneladas que cubre unas 70 mil hectáreas de tierra. En el cercano pueblo de Tabaco, 1,200 residentes locales indígenas $y$ afrocolombianos fueron desalojados por orden judicial con el fin de allanar el camino para la expansión de la mina. Los residentes locales afirman que nunca se contó con su consentimiento y los que se negaron a desplazarse eran sacados a golpes por la policía (PBI, 2011: 34). El Plan de Atención Integral para las Comunidades Indígenas llegó a cinco millones de dólares en 20 años, el equivalente a dos días y medio de producción de la mina (PBI, 2011:36), y la mina no ha hecho ninguna contribución significativa a la industria local. En cuanto al empleo, la empresa prefiere contratar a trabajadores extranjeros; si bien $45 \%$ de la población pertenece a la comunidad Wayúu, sólo representan $1 \%$ de los trabajadores de la mina (Benson, 2011). La Guajira cuenta con una tasa de pobreza de $70 \%$, una de las más altas del país, y los servicios de salud, educación y saneamiento son desgraciadamente inadecuados (Benson, 2011).

Las comunidades de los alrededores de El Cerrejón no son la excepción. De hecho, El Cerrejón ha sido señalado como el Posterboy para la indus- 
tria minera en Colombia, un modelo de responsabilidad corporativa sociales (RCS) para replicar en todo el país. ${ }^{1}$ Mientras que la inversión extranjera en el sector de la minería y la energía comenzó a despegar con las reformas neoliberales de la década de 1990, el boom minero en Colombia despega desde la primera década del nuevo siglo. El auge actual tiene sus raíces en el nuevo código minero de 2001 y los siguientes dos periodos presidenciales de Álvaro Uribe (2002-2010). El objetivo de Uribe era transformar el sector minero-energético de Colombia en una de las industrias más importantes de América Latina, mediante la estrategia de atraer a empresas multinacionales mineras para extraer los recursos del país a través del principio de la ventaja comparativa. Durante el gobierno de Uribe, la inversión extranjera en el sector minero-energético aumentó de 42 a 67\% del total de la inversión extranjera directa (IED) (Banco de la República, s/f). Para 2010, 60\% del territorio colombiano estaba bajo concesión minera o con solicitudes pendientes (Controloría General de la República, 2011: 131). En el marco del Plan Nacional de Desarrollo del actual presidente Juan Manuel Santos, la industria minera ha sido señalada como una de las cuatro «locomotoras» principales del desarrollo económico. El gobierno pretende aumentar la producción de crudo y gas en $40 \%$, la producción de carbón en dos tercios y la producción de oro en un tercio (DNP, 2010:220). ${ }^{2}$

Para el gobierno, la minería está destinada a proporcionar la fuerza motriz de un proceso de desarrollo capitalista exitoso; atraer inversión extranjera a través del principio de la ventaja comparativa que, supuestamente, dará lugar a la afamada promesa del Plan Nacional de Desarrollo de «prosperidad

/1/ El sitio web de El Cerrejón cita sus numerosos premios, tales como la British \& Colombian Business and Social Award de 2006, el premio de responsabilidad ambiental en 2009 y el título «Mejor experiencia a beneficio de la comunidad» en los premios nacionales de 2011.

12/ Según el Departamento Nacional de Planeación, se busca aumentar la producción de petróleo y gas de 990,600 a 1.4 millones de barriles diarios; la producción de carbón, de 74 a 124 millones de toneladas, y la producción de oro, de 53 a 72 toneladas por año (DNP, 2010: 220). 
para todos». Empero, en contra de esta tesis, como veremos más adelante, aquí argumentamos que la industria minera de Colombia es un claro ejemplo para demostrar que el desarrollo económico en la época neoliberal no es un proceso que levanta todos los barcos en una marea creciente. Hay ganadores y perdedores. Modelos especiales de desarrollo surgen en determinados lugares y tiempos no como cuestiones técnicas de gestión o gobierno, sino más bien como resultado de configuraciones de poder sociopolítico y las luchas entre las varias clases y sectores. La política minera actual se caracteriza principalmente por fuertes desigualdades en la distribución de los beneficios y los costos. Mientras que un puñado de corporaciones extranjeras monopolistas se apropian de los beneficios a una escala sin precedentes, los costos, que no son sólo económicos sino también sociales y ambientales, son transmitidos, o «externalizados» a los trabajadores, las comunidades y los que pagan el precio de la pérdida de tierras y recursos. Lejos de representar la «locomotora de desarrollo» que pretende el gobierno, el actual programa de desarrollo nacional está a punto de enviar a la nación por el camino del crecimiento económico con exclusión y despojo.

Frente a esta perspectiva, las opciones de las comunidades afectadas por la minería son limitadas. Pueden aceptar las condiciones impuestas por el modelo de desarrollo dominante, abandonar sus medios tradicionales de producción - en los casos afortunados recibir un mínimo de pagos compensatorios - para competir por los escasos empleos disponibles en los sitios mineros. O, de lo contrario, pueden resistir. Como veremos, esto ha sido el caso no sólo de las comunidades indígenas y los trabajadores de El Cerrejón, quienes lograron frenar la expansión de la mina y el desvío del río Ranchería, sino también de los cientos de nuevas movilizaciones generadas en torno a la industria minera en Colombia en los últimos años, lo cual ha dado un nuevo impulso a la larga trayectoria histórica de la lucha de clases del país. Dado la coyuntura actual, cabe destacar que la característica principal del llamado nuevo extractivismo es la de un conflicto directo entre las comunidades y el gran capital. En este contexto, este trabajo sostiene que, si bien en Colombia 
el boom minero no representa la «locomotora del desarrollo» prometido por el gobierno, bien podría echar más combustible a la otra locomotora: la de las fuerzas de la resistencia.

EL «NUEVO IMPERIALISMO» Y

LA LUCHA DE CLASES EN EL CENTRO Y LA PERIFERIA

La literatura académica sobre el reciente aumento en el capital extractivo ha sido influenciada en gran medida por el concepto de David Harvey de «acumulación por desposesión» (Harvey, 2005). Según la teoría de Harvey, la fase actual del «nuevo imperialismo» se caracteriza por un escenario mundial dominado por las corporaciones monopólicas, que se expanden a través del reclutamiento del poder del Estado imperial con el fin de abrir nuevas fuentes de inversiones rentables en la periferia. Las tendencias a la sobreacumulación son «arregladas» (fixed) mediante estrategias a menudo engañosas, fraudulentas y violentas de separación de las comunidades de sus tierras y recursos, la privatización de los activos públicos y la explotación intensiva de fuerza de trabajo. Éste es el marco teórico adoptado por Gordon y Webber, cuyo estudio de la minería en América Latina se centra en el papel del Estado canadiense imperialista en la facilitación de una «unidad canadiense corporativa de los espacios de acumulación de capital» (2007: 83). Sin embargo, mientras el modelo de Harvey propone una interpretación perspicaz desde la óptica del capitalismo global, cuando se aplica desde la perspectiva de los Estados periféricos, el modelo sólo proporciona un lado de la historia. Estrategias de acumulación por desposesión no son simplemente impuestas a las comunidades de la periferia de las potencias imperiales, sino más bien surgen como resultado de la configuración de poder de las clases dominantes en el Estado periférico. En el caso de Colombia, lo que puede ser descrito como un Plan de Desarrollo Nacional basado en la acumulación por desposesión, ha surgido como resultado de la evolución de las relaciones de poder de la clases domi- 
nantes y la lucha de clases desde abajo, junto con la interacción de estos procesos con las fuerzas internacionales de capital (veáse también O'Connor y Bohórquez, 2010). De ello se deduce que las luchas sociales que surgen en torno a la acumulación por desposesión son mejor entendidas como el producto de la evolución en la trayectoria histórica de la lucha de clases, sobre todo teniendo lugar en el ámbito nacional, y no como movimientos que operan en un escenario global, o incluso como movimientos que surgen para «confrontar el capital canadiense», como sostienen Gordon y Webber (2007). Las fuerzas internacionales pueden incidir y reconfigurar la lucha de clases a nivel nacional, pero sería un error entenderlas como sus determinantes principales.

El boom minero, o la incursión del capital transnacional extractivista, en Colombia ha condicionado y se ha visto condicionado por el panorama social, económico y político en el que llegó. Colombia es uno de los países más desiguales del mundo. El crecimiento sostenido del producto interno bruto (Рів) desde las reformas neoliberales de 1990 ha sido acompañado por un crecimiento sostenido de desigualdad, tal como se refleja en un aumento del coeficiente de Gini de 0.546 en 1990, en los albores de la era neoliberal, a 0.578 en dos décadas. El nivel de desigualdad social en la distribución de la riqueza y el ingreso es el segundo más alto en el continente (FESCOL, 2011).49\% de la población vive en condiciones de pobreza, cifra que es mucho mayor en los distritos mineros como Montecristo en Bolívar (91\%), Nechí en Antioquia (86\%), Maicao en la Guajira (83\%) y El Paso en Cesar (79\%). ${ }^{3} \mathrm{Al}$ igual que en la década de 1960, cuando décadas de «acumulación primitiva» (despojo del campesinado o la separación de los productores directos de la tierra en un proceso de expropiación violenta) generó un movimiento de lucha por tierras de gran alcance y un ejército de liberación nacional (las FARC-EP), la fuente principal de la pobreza es la distribución de tierras. Hoy en día, a pesar de la

${ }^{13 /}$ Cifras basadas en el Indice Multidimensional de Pobreza (IMP) de los datos del Dane de 2005 (La Silla Vacía, 2013). 
lucha por la tierra que ha atravesado cinco décadas, la característica predominante del campo colombiano es el destierro. El 63\% de la tierra permanece en manos de sólo $0.43 \%$ de los propietarios y $75.6 \%$ de la tierra cultivable se dedica a la ganadería extensiva (DANE, 2004), mientras que más de 120 mil colombianos mueren por desnutrición cada año. Los escuadrones de muerte paramilitares patrocinados por el Estado son responsables del asesinato de aproximadamente 500 mil personas, incluidos los líderes de la oposición, activistas y periodistas, y en particular, desde la década de 1980, han llevado a cabo el robo violento de tierra. Según un informe gubernamental, los paramilitares y los narcotraficantes ahora poseen casi la mitad de toda la tierra cultivable del país (Vicecontralor General de la República, 2007). Mientras tanto, se estima que cinco millones de colombianos han sido desplazados de hasta 10 millones de hectáreas de tierra (ABColombia, 2011). Entre 1986 y 2010, 2,800 sindicalistas fueron asesinados, cifra que hace que Colombia sea el país más peligroso del mundo para sindicalizarse. En el sector mineroenergetico, tres cuartas partes de los trabajadores están laborando por debajo de los estándares mínimos establecidos por la Organización Internacional del Trabalo (огт) (Villamil, 2013). En la última «apertura democrática» para un partido político de izquierda, en las décadas de 1980 y 1990, se formó la Unión Patriótica. En 2002, el movimiento terminó después del asesinato de aproximadamente cuatro mil miembros — entre ellos alcaldes, diputados, senadores y candidatos presidenciales - en manos de los grupos paramilitares. Los factores principales que caracterizan la minería de Colombia y el capital extractivo, o lo que Veltmeyer (2013) ha llamado el «imperialismo extractivista», se puede resumir en el siguiente esquema:

1. Un núcleo de empresas transnacionales (CTN) que se apropian de una porción cada vez mayor de las súperganancias obtenidas en la industria minera. Estas empresas capitalistas grandes y poderosas económicamente se basan, principalmente, en Occidente, particularmente en Canadá, Estados Unidos y Reino Unido. De las 20 mayores empresas mineras que operan en Colombia, siete son canadien- 
ses, cuatro son colombianas, tres son estadounidenses y cuatro son conglomerados que combinan dos corporaciones o más. ${ }^{4}$ Estas empresas están pasando por un proceso de concentración y centralización; de las 40 empresas mineras más grandes del mundo en 2003, en 2007 sólo había 27 y el resto había sido devorado en el proceso de las fusiones y adquisiciones (Dinero, 2008). Las CTN están en manos de los agentes de una clase gobernante mundial de inversionistas, financistas e industriales. Esta clase también ejerce un poder político de gran alcance mediante el control del Estado, que es estructurado con el fin de representar y defender sus intereses de clase, y por medio de instituciones tales como la Corporación de Desarrollo Económico y fundaciones privadas, centros de investigación y foros de política, tales como la Fundación Heritage y el Instituto Fraser. También prescriben políticas públicas en beneficio del capital social y alientan a los gobiernos nacionales a adoptar medidas que facilitan la operaciones del capital extractivo. A nivel nacional, las empresas dependen de la representación y los contactos políticos de las élites locales, como el primo de Santos, representante de Canadá TNC Medoro Resources en Colombia. La industria minera en los últimos años también ha visto el surgimiento de grandes empresas colombianas dentro del llamado «sector privado».

2. El apoyo del Estado imperial para garantizar y promover la extracción de recursos a favor de sus CTN. Tradicionalmente, Colombia ha sido un pilar medular del imperio de Estados Unidos en América Latina en términos de proporcionar apoyo a la agenda geopolítica de «seguridad», así como un proveedor de recursos energéticos (veáse Petras, 2000). Actualmente, es el séptimo proveedor más importante de petróleo de Estados Unidos. Desde finales de 1990, con el surgimiento de grandes corporaciones mineras canadienses, el Estado canadiense ha tenido una influencia cada vez más poderosa en el sector minero-energético. El poder estatal también se ejerce mediante las organizaciones internacionales

14/ Entre los mayores, se encuentran внр Billiton (Australia), Rio Tinto (Reino Unido), Xstrata (Suiza y Reino Unido), Anglo American (Reino Unido), Barrick Gold (Canadá), Muriel Mining (Estados Unidos), Pacific Rubiales (Canadá), Greystar/Eco Oro (Canadá) y Drummond (Estados Unidos). 
e instituciones financieras que representan sus intereses, tales como el Banco Mundial, el Fondo Monetario Internacional (FMI) y la Agencia Canadiense de Desarrollo Internacional (CIDA, por sus siglas en inglés).

3. El apoyo del cuerpo de la élite de la clase dirigente nacional para proporcionar las condiciones necesarias para la entrada de las empresas extractivas. La élite, así como la clase dirigente, es normalmente sujeta a disputas entre facciones y la división política. En Colombia, la élite dentro de la clase dominante y gobernante es representada por dos bloques. Por un lado, está la élite oligárquica rural compuesta por oficiales militares y paramilitares, narcotraficantes, grandes propietarios de tierras dedicadas a la ganadería y la agroindustria, los políticos conservadores y los líderes de la Iglesia. El representante más destacado de este grupo es el ex presidente Álvaro Uribe. Por otro lado, está la élite transnacional, modernizante y urbana de los capitalistas industriales y financieros, junto con algunos agroindustriales. Esta clase ha sido representada por la mayoría de los presidentes de los últimos años, entre ellos el actual presidente Santos.

4. La promoción de un modelo de desarrollo nacional basado en la ideología de la «globalización», o la necesidad de insertar las economías nacionales en el mercado mundial. Esto concede especial prioridad a un modelo de crecimiento económico impulsado por la inversión extranjera directa (IED), que se siente atraída por el principio de la ventaja comparativa y la creación de la «confianza de los inversionistas». El sitio web del Ministerio de Minas y Energía declara, orgullosamente, que «según Doing Business [sitio web del Banco Mundial] somos el país con el mejor clima de negocios en Latinoamérica». Citando como ejemplo, hace la referencia a diversas exenciones fiscales sobre la extracción de materia prima, así como el hecho de que Colombia «tiene el segundo régimen laboral más flexible en América Latina», con un salario de un décimo comparado a Estados Unidos (Ministerio de Minas y Energía, s/f).

5. La adopción de estrategias militares para despejar y asegurar el camino del capital extractivo en el pasado a través de una alianza entre los operativos contrainsurgentes estadounidenses de la guerra fría, las empresas transnacionales, los sucesivos gobiernos de Colombia y el bloque de la élite rural. Estas estructuras, 
en gran parte, hoy persisten en la forma de la guerra contra las drogas del Plan Colombia, nuevos grupos paramilitares y las fuerzas estatales. Como se verá más adelante, los proyectos militares han servido a los intereses del capital extractivo para «despejar» la tierra y los recursos de las comunidades locales, la represión de la fuerza de trabajo y la eliminación de la oposición política de los partidos políticos, movimientos sociales y periodistas.

6. Distribución altamente desigual de los beneficios sobre la base de las divisiones entre clases y la división centro-periferia entre las naciones. El pequeño núcleo de empresas transnacionales es capaz de aprovechar los mecanismos de transferencia de excedentes, la apropiación de la tierra y de los recursos de las comunidades, la explotación de una fuerza de trabajo precaria y reprimida. A través de estas estrategias son capaces de capturar porciones sin precedentes de la utilidad social o, en otras palabras, cosechar súper-ganancias. En el espacio de apenas dos años, entre 2009 y 2011, las ganancias operativas en el sector de la minería casi se duplicaron, de 15 mil millones a 28 mil millones de dólares (Superintendencia, 2012: 4). Esto se ha logrado a través del ejercicio del poder político y militar que ha permitido que las empresas mineras se apropien de las tierras y los recursos a cambio de una cuota mínima de regalías e impuestos, y una distribución pésima de las ganancias con los trabajadores y comunidades locales. En términos económicos, la minería representa un drenaje en la economía nacional; en 2010, por cada dólar que ingresó al país en forma de IED en el sector minero y energético, 1.22 sale en la forma de dividendos y remesas de utilidades (Valencia, 2012: 14). Con respecto a las regalías e impuestos, de acuerdo con los cálculos de un economista contratado por el gobierno, las regalías en el sector minero en 2009 ascendieron a $29 \%$ para toda la minería, incluidos los hidrocarburos, y $25 \%$ si se excluyen los hidrocarburos (citado en ABcolombia, 2012: 21). Sin embargo, según los cálculos de las exenciones, $51 \%$ de impuesto sobre la renta de toda la minería, incluidos los hidrocarburos, fue pagado en forma de exenciones, cifra que llegó a 90\% para minería sin contar hidrocarburos (ibid). La pérdida total para el gobierno en la forma de exenciones ascendió a 2.2 billones de dólares en 2009 , cifra que es superior, por ejemplo, al total del presupuesto que se gasta en 
víctimas del conflicto o, de hecho, en todo el presupuesto de salud. Otro componente clave de la capacidad de las empresas para hacer súper-ganancias de la extracción de recursos ha sido la exclusión de los costos ambientales y sociales que acompañan el proceso de extracción, pues son las comunidades locales y los trabajadores quienes, en gran medida, pagan la factura.

7. Asunción altamente desigual de los costos. La minería a gran escala no sólo ofrece pocos beneficios a otros sectores de la economía, pero los amenaza a través de los efectos de la enfermedad holandesa. ${ }^{5}$ Entre 2000 y 2011, mientras que la participación de la minería en el PIB aumentó del 6 al 11\%, el de la agricultura cayó 8 a 6\% y la industria cayó del 14 al 12\% (Banco de la República, s/f). Los que pagan el precio más alto de la incursión del capital minero, sin embargo, son los trabajadores y los pueblos indígenas afrodescendientes, comunidades campesinas y pequeños mineros en la fase actual de un proceso intensivo y frenético de «acumulación por desposesión» (Harvey, 2005). Esto se caracteriza por la mayor explotación de la fuerza laboral en la división internacional del trabajo, la privatización de las empresas mineras estatales, la apropiación y la contaminación de los recursos locales y el abastecimiento de agua, la reconfiguración de los derechos de propiedad en favorecer al gran capital y el desplazamiento territorial de millones de comunidades indígenas y campesinas.

8. Un nuevo impulso para las fuerzas de resistencia, originado en los conflictos generados por la industria minera. Nuevas contradicciones y formas de despojo que rodean los mecanismos actuales de extracción de recursos naturales han estado acompañados por el surgimiento de un nuevo conjunto de actores que participan en las movilizaciones: los trabajadores en huelga; las comunidades indígenas, afrocolombianos, campesinas y mineras desplazadas, y las comunidades

\footnotetext{
${ }^{15 /}$ La enfermedad holandesa ocurre cuando la afluencia de dólares hace que la moneda se aprecie, lo que aumenta el precio de la producción local y la reducción de la competitividad, tanto en los mercados locales e internacionales. El peso colombiano ha tenido una de las tasas más altas de apreciación en el mundo en relación con el dólar, con una revalorización de 38\% entre 2003 y 2012 (Banco de la República, s/f).
} 
urbanas amenazadas por la pérdida de suministro de agua y los activistas ambientales. Con estos nuevos actores ha llegado un nuevo conjunto de estrategias, demandas y propuestas alternativas.

Bajo este marco, las siguientes tres secciones examinan la evolución de la economía política nacional e internacional que han allanado el camino para el auge de la minería. Luego, se revisan los nuevos actores y puntos de conflicto generados en torno a las dinámicas del extractivismo contemporáneo.

\section{Preparando el camino para EL CAPITAL EXTRACTIVISTA}

¿Por qué se desencadenó la entrada de ied basada en la extracción de materias primas en la primera década del siglo xxi? Por supuesto, hubo un aumento de los precios de las principales exportaciones mineras de Colombia: desde 2001, los precios del oro han aumentado en 4.5 veces; del carbón, 2.5, y del níquel, 4.7. También hubo cambios en la coyuntura geopolítica. Colombia ha representado durante mucho tiempo un aliado estratégico para los intereses energéticos y de seguridad de Estados Unidos. A mediados de los noventa, con reservas estimadas en 150 mil millones barriles, Colombia llegó a ser el séptimo proveedor petrolero de Estados Unidos.

Sin embargo, desde finales de la década de los noventa, Canadá también ha intervenido como actor internacional importante. Si el capital canadiense reproduce una papel significativo en la extracción de petróleo y gas colombianos desde la década de los veinte, con los programas de reformas neoliberales de la década de los noventa Colombia fue considerado por el gobierno canadiense como un destino clave para sus inversiones en el sector de la minería. El Departamento Canadiense de Asuntos Exteriores y Comercio Internacional (DFAIT, por sus siglas en inglés) explicaः «La inversión extranjera en sectores claves [de Colombia], tales como los programas de infraestructura y 
privatización, ha ofrecido nuevas posibilidades a largo plazo para los inversores empresariales canadienses» (Ismi, 2012). En 1996, cid donó 11.3 millones de dólares al Ministerio de Minas y Energía para «mejorar la capacidad institucional» de este ministerio y regular los sectores de hidrocarburos, minería y energía. «Una serie de medidas de desregulación y reestructuración» mejoraría las perspectivas de Colombia para atraer la inversión extranjera.

La influencia de este «apoyo» se demuestra claramente en el nuevo Código Minero de Colombia de 2001. Introducido como parte del paquete de reformas neoliberales bajo los auspicios del Banco Mundial y el ciDA, el código establece el marco legal que permite la incursión de la inversión extranjera en la minería. La minería fue declarada una «actividad de interés público», lo que permite la expropiación unilateral de la propiedad privada. Fueron levantadas las restricciones a las áreas abiertas para la exploración y reducidos los impuestos a las empresas. Los títulos mineros se otorgaron bajo el principio de «primero en tiempo, primero en el derecho». La participación del Estado en la extracción fue suprimido y su papel fue relegado a la de regulación y recolección de regalías (Fierro, 2012: 16,38). Se establecieron tasas fijas para las regalías, por ejemplo, a $0.4 \%$ en la producción de carbón y oro (Pardo, 2012: 9). La empresa minera estatal Minercol fue liquidada (junto con el sindicato nacional minero, SintraminerCol). La corporación de carbón en El Cerrejón, Carbocol, fue vendida a un consorcio extranjero - compuesto por Exxon Mobil, Anglo American, вHP Billiton y Glencore Internacional por 384 millones de dólares-, muy por debajo de su valor estimado, bajo presión del FMI, lo cual desencadenó un auge de inversión extranjera en el sector. En 1996, la minería representaba 2.2\% de la inversión extranjera total. Para 2001, esta cifra había aumentado a 26\% (Banco de la República, s/f). La inversión canadiense en el sector de minería e hidrocarburos se disparó de 1.4 millones de dólares en 1999 a 663.9 millones de dólares en 2000 (Banco de la República, s/f).

El carácter de este boom a la vez determinó y fue determinado por las dinámicas del conflicto armado. La creciente cantidad de tropas guerrilleras se enfocaba cada vez mas en las áreas de importancia estratégica en términos de 
recursos naturales, lo cual tuvo un impacto importante en las zonas petroleras, como el Putumayo, donde la producción de petróleo disminuyó desde un máximo de 80 mil barriles diarios en 1980 a menos de 10 mil en 2003, y en Caño Limón en Arauca, que había recibido 170 ataques de la guerrilla sólo en 2001 (Leech, 2004). En este contexto, el auge en los años noventa de los paramilitares, en alianza con los operativos contrainsurgentes de Estados Unidos, los políticos y los empresarios nacionales, que consistió en un apropiación de 11 millones de hectáreas de tierra y el despojo de cinco millones de personas, también está estrechamente ligado a la nueva incursión de IED. En un momento de lucidez, el jefe paramilitar Carlos Castaño declaró que «nosotros [los paramilitares] siempre hemos proclamado que somos los defensores de la libertad de empresas y de los sectores industriales nacionales e internacionales» (citado en Stokes, 2006: 10).74\% de las violaciones de los derechos humanos tiene lugar en las regiones minero-energéticas (que actualmente representan $32 \%$ del territorio nacional) y $87 \%$ de la población desplazada en la actualidad provienen de estas zonas. Entre 1995 y 2002, un total de 7,500 asesinatos fueron cometidos en estas regiones (Ramírez, 2011). Es precisamente tras el auge paramilitar y el pacto entre las facciones de la élite - por un lado, el bloque rural de terratenientes, narcotraficantes, paramilitares, miembros del Congreso y la Iglesia, por otro lado, la élite transnacional de comerciantes, banqueros e industriales - que llega el presidente Uribe al poder en 2002.

Esta nueva alianza también contó con una representación importante de las empresas de la gran minería. Los ejecutivos de empresas como AngloGold Ashanti, Drummond y Glencore Greystar aprovecharon las reuniones periódicas con los políticos nacionales (Cuervo, 2012: 141). El grupo de lobby llamado «el Sector de la Minería a Gran Escala», que representa a las empresas mineras nacionales y multinacionales, organiza eventos regulares con los ministros del gobierno como oradores principales. Uribe es acusado de haber participado en reuniones entre Drummond y los paramilitares. AngloGold Ashanti hizo acuerdos con el presidente Uribe y funcionarios de las agencias de Ingeominas mineras reguladoras con el fin de eliminar los obstáculos ambientales en las 
regulaciones mineras (ibid). Funcionarios de Ingeominas pasan a trabajar para AngloGold Ashanti. Un primo del actual presidente Santos es el presidente nacional de la minería de oro canadiense Medoro multinacional y el ex canciller Araújo es actualmente jefe nacional del oro canadiense Gran Colombia. Es, de esta manera, que los actores clave del auge minero han permeado las configuraciones de los bloques nacionales de élite y las clases dominantes.

\section{El EXTRACTIVISMO EN GUERRA}

$$
\text { (2002-2010) }
$$

La política minera de Uribe se basaba en dos pilares principales: primero, como veremos mas adelante, en una estrategia sin precedentes de desregulación estatal, y segundo, en el desencadenamiento de la violencia patrocinada por el Estado. Un componente principal de esta campaña, supuestamente de «Seguridad Democrática», fue la asignación de unidades militares para proteger al sector minero. Dos tercios de las tropas debían dedicarse a salvaguardar la infraestructura petrolera y minera. En la región de Santander, por ejemplo, las Fuerzas Armadas Revolucionarias de Colombia (FARC) y el Ejército de Liberación Nacional (ELN) habían estado cobrando «Vacunas» (impuestos) a la empresa Greystar minera canadiense de oro, en forma de pagos a las escuelas locales, clínicas e infraestructura. Tras el secuestro de uno de sus subcontratistas y la salida de las tropas estatales, Greystar se retiró de la región en 1999. Sin embargo, en mayo de 2002, Greystar, junto con gobiernos de Canadá y Estados Unidos, participaron en las conversaciones con Uribe (Cumming, 2004). Resulta que, en su toma de posesión en el poder, Uribe estableció dos bases militares en la región para combatir la guerrilla y obligó a 180 mineros artesanales (declarados «mineros ilegales») a abandonar el sitio (O'Connor y Bohórquez, 2010: 104). La IED en el sector minero se disparó de 466 millones de dólares en 2002 a 2.2 mil millones de dólares en 2005 (Banco de la República, s/f). 
Sin embargo, la política de guerra total muy pronto tomó un aspecto desalentador en tres frentes. Primero, con una tasa creciente de ataques guerrilleros, no hubo ningún indicador claro de que el gobierno estaba ganando. En segundo lugar, con un déficit de $6 \%$ y una deuda nacional de $54 \%$ del рів, el presupuesto se estaba agotando. En tercer lugar, la alianza temporal entre el bloque mafioso de la élite rural y el bloque de las élites transnacionales se estaba acabando. La introducción de un «impuesto élite» para financiar el gasto militar estaba provocando una rebelión en los sectores empresariales (Brittain, 2007).

Ante las crecientes presiones internas generadas por los costos de un programa militar fracasado, Uribe apostó desesperamente por el sector minero. Como Richani (2012: 134-135) ha argumentado: «los imperativos crecientes de guerra llevaban al gobierno a integrarse a la economía mundial basado en el principio de la "ventaja comparativa”, un eufemismo para asignar la posición económica de Colombia en la división global del trabajo, lo que limita su economía a la exportación de unos pocos cultivos comerciales de minería, gas, petróleo y servicios (café, flores cortadas y aceite de palma)». En otras palabras, ningún esfuerzo sería escatimado para atraer el interés extranjero en el sector minero. Según la observación del presidente regional de una empresa petrolera en Colombia, «el gobierno está literalmente desesperado por atraer a las empresas mediante la presentación de todo tipo de concesiones» (NY Times, 24 de octubre de 2004, citado en Richani, 2010: 133). Uribe promueve una segunda fase del Plan Colombia, titulado «Recuperación Social del Territorio», que incluye la expansión militar en 53 regiones de importancia estratégica donde operan grandes empresas como вр, Repsol y Harken Energy, y la creación de dos batallones para proteger a las empresas mineras y energéticas (Ramírez, 2011; Ismi, 2012). Esto fue acompañado por una estrategia de cooptación de un millón y medio de informantes civiles regionales y un aumento de $200 \%$ de la violación de los derechos humanos en estas regiones (Ismi, 2012).

Uribe se dedicó a un proyecto desenfrenado de controles reglamentarios, la aplicación de nuevas privatizaciones y la apertura del país al libre comer- 
cio, la firma de acuerdos con China, Estados Unidos y Canadá. El instituto regulatorio, Ingeominas, fue reducido a 50 funcionarios y asignaron fondos suficientes para verificar los pagos de los derechos de más de cuatro mil títulos mineros. Durante este periodo, más de nueve mil títulos mineros fueron adjudicados, incluyendo parques nacionales y reservas indígenas, en lo que el actual ministro de Minas y Energía más tarde llamó una «piñata de concesiones mineras». Sólo una empresa, Anglo Gold Ashanti, consiguió 496 títulos de explotación sobre 825 mil hectáreas y títulos de exploración en dos millones de hectáreas más (Pulido y Osorio, 2011).

De acuerdo con las últimas exigencias del FMI, Ecopetrol, la empresa petrolera estatal, fue liquidada y dividida en tres empresas. Más adelante, el $20 \%$ de Ecopetrol sería colocado en el mercado de valores. Mientras que las empresas reformadas seguían bajo control estatal, ya no estaban obligados a participar en la perforación. Los nuevos acuerdos eliminaron la participación estatal en contratos de explotación petrolera y las regalías mínimas fueron reducidas de 23\% a 8\% (Leech, 2006: 150). La primera empresa en beneficiarse fue Harken Energy, una compañía con estrechos vínculos con el ex presidente George Bush (Leech, 2004). Lo que quedaba de Ecopetrol era para cubrir la infraestructura, los oleoductos y los costos de transporte con el fin de atraer nuevas inversiones (Richani, 2010: 135).

Una serie de beneficios se ofrecen a las empresas extractivas en forma de exenciones fiscales, deducciones por las ventas de activos fijos que pasó de 30 a 40\%, eliminación de impuestos sobre servicios públicos y concesión de subsidios al combustible (Pardo, 2012: 15). Según la Ley 963 de 2005, el $20 \%$ de los hidrocarburos fue sustituido por una tasa negociable - que puede ser de tan sólo 8\%-, a los inversores extranjeros se les dio la misma igualdad de derechos que los nacionales y los derechos plenos de remesas les fueron concedidos (Zúńiga, 2010). Los nuevos contratos firmados con más de 700 empresas incluyeron artículos que estipulan que el pago de regalías no podía ser aumentado en un periodo de 20 años, y en el caso en que las nuevas leyes redujeran los pagos de regalías, las empresas tendrían la oportunidad de rene- 
gociar los contratos (Pardo, 2012). Las nuevas medidas no pasaron inadvertidas. El instituo canadiense Fraser Institute, promotor del proyecto Libertad Económica en el Mundo, poco después informó felizmente que «Colombia mostró una mejoría significativa [...] La mejor puntuación podría ser el resultado de una mayor confianza a la comunidad minera en el país, debido a su mayor estabilidad política y la seguridad» (Fraser Institute, 2010).

La nueva política desató un boom minero que superó aun los sueños de Uribe. El objetivo declarado de Uribe había sido amplificar el área bajo las concesiones mineras en 50\% (Fernández y Valencia 2010: 13). Mientras que durante la administración Pastrana (1996-2000) 221 mil hectáreas de tierra estaban bajo concesiones mineras, durante el gobierno de Uribe esta cifra ascendió a 7.4 millones de hectáreas (ABcolombia, 2011); su objetivo fue superado por 22 veces. La IED en los sectores de minería y energía aumentó diez veces entre 2002 y 2010 , pasando de 466 millones a 4.5 mil millones de dólares, del 42 al 67\% de la IED (Banco de la República s/f). Esto fue acompañado por un aumento en el número de empresas petroleras canadienses que operan en Colombia, de siete en 2006 a 15 en 2012. Entre 2002 y 2010, la producción de carbón aumentó $80 \%$ y la producción de petróleo aumentó $36 \%$. Entre 2006 y 2010, la producción de oro aumentó 340\% (Ministerio de Minas y Energía, 2011).

Los dos booms que caracterizan este periodo, el capital extractivo y la violencia política, están estrechamente vinculados de varias maneras. En primer lugar, un bloque mafioso de la élite rural fue capaz de llegar al poder mediante el aprovechamiento de la priorización de una política de «seguridad» de Estados Unidos, Canadá y las empresas multinacionales, quienes buscaban protección frente a las amenazas de la guerrilla; de ahí se formó una alianza basada en intereses mutuos. En segundo lugar, las reformas neoliberales allanaron el camino para una oleada de varios mecanismos de acumulación por desposesión, es decir, la privatización, la superexplotación y la separación de las comunidades campesinas, indígenas y afrocolombianas de sus tierras y medios de producción. Este proceso fue acelerado por la alianza mafiosa de 
los bloques de élites a través de las reformas institucionales y de la violencia militar y paramilitar. Por último, la estrategia de guerra total, adoptada por este bloque mafioso, requería de una vaca de leche para financiar sus grandes costos; esa vaca tomó la forma de las rentas mineras. De esta manera, el capital extractivo ha generado y ha sido generado por la violencia estatal.

\section{¿Extractivismo en PAZ?}

(DE 2OIO A LA FECHA)

Desde la salida de Uribe y la elección de su ex ministro de Defensa, Juan Manuel Santos en 2010, la política minera se ha acelerado en la misma dirección. En su Plan Nacional de Desarrollo 2011-2014, el nuevo presidente manifestó su objetivo de «prosperidad para todos, más empleo, menos pobreza y más seguridad». Esto se lograría sólo si Colombia se convertía en uno de «los cinco principales destinos para la inversión extranjera en América Latina, multiplicando la producción minera nacional y garantizando la estabilidad tributaria para los inversores». El impuesto sobre la renta se redujo de 33 a 25\%, cifra que no tiene en cuenta las deducciones y exenciones, que llegaron a un billón de dólares en 2011 (Pardo, 2012: 16). En 2011, después del primer año de la administración Santos, el número de concesiones mineras se elevó a 8.4 millones, y en 2012 Santos abrió dos «distritos estratégicos mineros» para subastar a los inversores internacionales, lo cual culmina en un total de 20.5 millones de hectáreas (ABcolombia, 2012).

Como hemos visto en el apartado anterior, la guerra en Colombia ha servido para mantener el poder del bloque de las élites rurales, cuyos intereses estaban representados en la presidencia de Uribe. Santos representa una facción de la élite conectada pero distinta: la élite transnacional de los empresarios y financieros. La élite transnacional había hecho una alianza con las élites de la mafia rural para allanar el camino a las reformas neoliberales y el capital extractivo a costa de la mayoría de la población. Sin embargo, el bloque de la élite 
rural tiene más que ganar con la perpetuación de la guerra. La reciente apuesta del presidente Santos a las negociaciones de paz es un signo de que algunas facciones de la élite se están alejando del nexo entre guerra y extractivismo.

La guerra sigue significando un costo importante; el presupuesto militar sigue representando alrededor de la tercera parte del PIB, mientras que la deuda nacional se ha mantenido en 52\% del рів. Ademas, la guerra ha representado una amenaza a la inversión extranjera cada vez más importante desde 2011, ya que las FARC intensificaron la operación militar dirigida al sector extractivo. Según las propias cifras del gobierno, en 2011 el secuestro de los empleados en este sector aumentó en 377\% y los ataques a los oleoductos aumentaron 253\% (Ministerio de Defensa, 2012). Los ataques contra oleoductos y ferrocarriles de carbón han resultado costosos, con pérdidas estimadas en 400 millones de dólares al año (Sequera, 2012). Un acuerdo entre las FARC y el ELN se hizo en febrero de 2013 para dirigirse específicamente a la minería en las zonas de petróleo y oro de Antioquia. El Ministro de Hacienda estima que si las negociaciones de paz logran poner fin al conflicto, el рів de Colombia podría crecer entre uno y dos puntos porcentuales extras anuales (ibid). No cabe duda de que la inversión extranjera en el sector minero ha sido uno de los principales factores de motivación para la reciente iniciativa de paz de Santos con las FArc y el ELN.

El aumento de la hegemonía canadiense también ha tenido un impacto en el panorama político colombiano. En 2011, eran canadienses el 65\% de las empresas de exploración de minerales y metales y más de $75 \%$ de todas las empresas de exploración de petróleo y gas (North-South Institute, 2012). Mientras que el gobierno de Bush había favorecido un enfoque abiertamente militarista para brindar facilidades al capital extractivo, el énfasis canadiense ha sido en las reformas institucionales, la ampliación de los mercados de tierras, medidas de estabilidad, las ong y la Responsabilidad Social Corporativa (RSC). En 2011, el Ministro Canadiense de Cooperación Internacional desvió sus fondos hacia las organizaciones no gubernamentales que trabajan en colaboración con las empresas mineras (PAsc, 2012). La Embajada de Canadá 
se ha asociado con Fundación Ideas para la Paz (FIP), que ofrece consejos de seguridad para los inversionistas canadienses que quieren invertir en Colombia y busca crear las bases para el diálogo entre la sociedad civil y las empresas mineras en las directrices de RSC (Mining Watch Canada, 2009).

Mientras que el gobierno de Uribe se había alimentado de un discurso reaccionario basado en los miedos de la Guerra Fría para mantenerse en el poder, reprimir la oposición y militarizar a la nación, para el bloque de la élite transnacional — representada por el gobierno de Santos— las FARC son una de las pocas barreras que quedan a la inversión extranjera. De hecho, fue a través de la Fip que los empresarios nacionales y altos ejecutivos de las corporaciones multinacionales eran capaces de presionar a favor de las negociaciones de paz, así como asegurarse de que las condiciones en la mesa de negociaciones eran aceptables para este grupo (Vanguardia, 2012). Según un representante de la FIP, «estos empresarios entienden que la sostenibilidad de su negocio depende de su capacidad para generar un clima de negocios estable» (Vanguardia, 2012, traducción mía). De hecho, Santos ha afirmado con toda claridad que el modelo extractivo y la inversión extranjera son puntos firmes frente a la mesa de negociaciones. Además, la reforma agraria y el desarrollo rural, temas netamente no negociables para Uribe, constituyen el primer punto de las negociaciones en curso. No es casualidad que mientras que los altos ejecutivos pueden estar en la mesa de negociación, por primera vez los integrantes de la Federación Colombiana de Ganaderos (Fedegan) no están presentes.

Si bien el resultado de las negociaciones aún no se ha visto, las medidas tomadas por el gobierno de Santos pueden representar los primeros pasos de un cambio en el panorama económico y político. Para la élite transnacional, que pretende ampliar, modernizar y regular los mercados de tierras, una guerra contrainsurgente se ve como un contratiempo anacrónico. La expansión del extractivismo requiere regulación y títulos de propiedad claros. Sin embargo, la incursión del capital extractivo en Colombia fue acompañado por la denuncia de la comunidad internacional de que empresas transnacionales 
estaban operando en tierras usurpadas (ver ABcolombia, 2011). La élite del bloque rural se ha beneficiado de la guerra interna y también este bloque es el que tiene más para perder ante un eventual acuerdo de paz. Ésta es una razón clave por la que, por primera vez desde la década de 1960, las fricciones serias entre la oligarquía rural y la élite transnacional están empezando a surgir.

Hemos visto cómo el surgimiento del auge minero en Colombia ha jugado un papel medular en la evolución de las relaciones de poder entre los bloques de élite. La evolución de estos bloques está también ligada a la lucha de clases desde hace tiempo en Colombia. Las negociaciones de paz, actualmente en curso, con el gobierno de Santos representan una apertura fundamental para los movimientos sociales del país - las comunidades indígenas, afrodescendientes, campesinos y pequeñas comunidades mineras, sindicalistas y activistas- que han sufrido asesinatos, estigmatización y persecución durante décadas de guerra sucia. Como Zibechi ha señalado recientemente, «para los movimientos sociales, el fin de la guerra no significa paz, sino la continuación de la lucha en un ambiente más favorable» (2012).

El final del conflicto impulsa el camino para que la lucha de las comunidades contra las multinacionales y la política minera del gobierno continue en el ámbito democrático. Con antecedentes en los partidos democráticos de izquierda que representan a los movimientos sociales — como la Unión Patriótica, y más recientemente la movilización agraria de 2007, las movilizaciones a nivel nacional en las celebraciones del Bicentenario de 2010, el Encuentro de la Paz en Barrancabermeja y el foro contra el desplazamiento por megaproyectos en Cali en 2011_, se formó la Marcha Patriotica en 2012. La fundación del movimiento fue marcada con la movilización de 120 mil personas en la Plaza de Bolívar de Bogotá, quienes representaban a campesinos, indígenas y comunidades afrodescendientes, sindicatos, grupos de estudiantes y activistas. Las movilizaciones han incluido foros sobre políticas de desarrollo alternativo en áreas como la minería, la agricultura, el trabajo y el derecho a la tierra. En este contexto, la siguiente sección analiza cómo la política minera actual tiene el potencial de generar nuevas fuerzas para tales movimientos. 


\section{LA LOCOMOTORA DE LA RESISTENCIA}

Hemos visto cómo el auge de la minería en Colombia se ha visto acompañado por una reconfiguración en los actores de la élite, los arreglos institucionales y las estrategias de acumulación. Eso es sólo un lado de la historia. Por otro lado, podemos ver cómo estas dinámicas a nivel local, nacional e internacional han traído nuevas contradicciones entre los intereses del capital y los intereses locales de indígenas, campesinos, comunidades mineras afrodescendientes, pequeñas y medianas empresas, trabajadores y otros grupos afectados. Por supuesto, el conflicto territorial entre las comunidades locales y los terratenientes, las empresas y el Estado, así como los litigios sobre salarios y condiciones de trabajo siempre han jugado un papel significativo en el proceso de desarrollo capitalista en la periferia. Sin embargo, con el fin de allanar el camino para esta última fase de desarrollo extractivista, el Estado ha implementado una serie de medidas, tales como las privatizaciones, cambios en los derechos de propiedad, expulsiones y apropriaciones de tierra y reformas laborales, los costos de los cuales son «externalizados» en las poblaciones más vulnerables. Es en este proceso que las nuevas fuerzas de resistencia son generadas y la trayectoria histórica de la lucha de clases se vuelve a configurar.

Durante la última década, se ha visto un aumento en las movilizacies sociales en torno a la extracción de recursos. Según un estudio del instituto de investigación social CINEP, entre 2001 y 2011 hubo 274 movilizaciones sociales asociadas con la extracción de recursos. El número de movilizaciones ha aumentado de forma constante desde 2005 (CINEp, 2012). Tradicionalmente, los movimientos laborales ocupaban el lugar central en los conflictos sociales en torno a la extracción de recursos, en relación con los salarios y condiciones de trabajo. Sin embargo, los diversos impactos del boom minero se han acompañado de una reconfiguración de los actores sociales y las demandas de las movilizaciones contra la industria. El mismo estudio destacó que un pequeño aumento en las movilizaciones de los trabajadores ha sido acompañada por 
la entrada de nuevos actores en el escenario de los movimientos en contra de la extracción de recursos naturales. Mientras que los trabajadores asalariados constituyen la mitad de los manifestantes en este periodo, el 25\% de los participantes proviene de comunidades rurales, incluso de grupos étnicos en $10 \%$ y $15 \%$ de campesinos; el $13 \%$ eran mineros de pequeña escala y $12 \%$ procedía de comunidades urbanas (CINEP, 2012).

La nueva dinámica de movilizaciones en contra de la extracción de recursos en gran medida refleja los cambios estructurales que rodean la industria extractiva. La clave para la capacidad monopólica de las empresas mineras para extraer superganancias es su capacidad para ejercer una influencia política. Tal influencia permite la apropiación de una porción extraordinariamente grande de la tarta mediante estrategias engañosas, fraudulentas y violentas. Tales estrategias incluyen un asalto brutal contra el poder colectivo del trabajo, la privtización de empresas estalaes y la apropiación, a menudo violenta o engañosa, de la tierra y los recursos de las comunidades locales, además de eludir el pago de la compensación por la totalidad de los costos sociales y ambientales.

No es posible dentro de este artículo documentar todos las estrategias del extractivismo contemporáneo que ha generado el nuevo ámbito de conflictos sociales. Sin embargo, cabe resaltar que en Colombia los puntos claves de polarización han emergido en casos de conflicto directo entre las comunidades y las empresas mineras, a causa del despojo violento y legal de tierra y recursos, especialmente el agua. Un caso revelador viene de la región del sur de Bolívar, que produce $42 \%$ del oro del país. Durante las décadas de los ochenta y noventa, la región había llegado a ser poblada por campesinos desplazados que extraen oro en pequeña escala. En 1997, sin embargo, las fuerzas de las Autodefensas Unidas de Colombia (AUC) ingresaron con la intención explícita de «limpiar la región para entregarla a las corporaciones multinacionales, ya que generarán empleos y mejorarán la zona» (citado en Richani, 2005: 122). Entre 1997 y 2007, siete aldeas fueron saqueadas, 380 miembros de la comunidad fueron asesinados (incluyendo sindicalistas mineros artesanales) y 36 mil personas fueron desplazadas de la región (рві Colombia, 2011). 
Mientras tanto, a raíz de los cambios en las leyes mineras, tres corporaciones pugnaron por comprar los títulos mineros de la zona: la primera, Conquistador Goldmines, es una filial canadiense/colombiana de propiedad estadounidense Corona Goldfields (a través de la compañía de San Lucas), mientras que las otras dos, Sur American Gold у в мR, son canadienses basadas en las empresas (O'Connor y Bohórquez, 2010: 101; Richani, 205: 123).

La apropiación del agua también representa un punto central de polarización. La mitad de los páramos del mundo queda en territorio colombiano y estos ecosistemas únicos andinos suministran más de $70 \%$ del agua potable de la nación (El Espectador, 2011). El código minero de 2001 desregula las protecciones ambientales. Aunque en el código se aumentaron las áreas de páramos protegidas, para 2010, 391 títulos mineros se habían adjudicado 109 mil hectáreas de páramo (PBI, 2011), lo cual cortará el suministro de agua de las comunidades y pueblos enteros. La situación provocó en 2011 el anuncio de la Contraloría General de que «Colombia está al borde de un colapso ambiental sin antecedentes en nuestra historia» (ABcolombia, 2012:7). Uno de los ejemplos más notables de esa coyuntura ha sido la controvertida adquisición de títulos mineros para proyectos de extracción de oro a cielo abierto en $30 \mathrm{mil}$ hectáreas en el páramo de Santurbán en Santander por la canadiense Greystar (ahora Eco Oro). El proyecto inicial propuso el uso de 40 toneladas de cianuro por día, tomando el suministro de agua de dos millones de habitantes de la capital del estado de Bucaramanga y el área circundante. Cabe destacar que la movilización masiva y recolección de 75 mil firmas en esa ciudad ha resultado en la postergación del proyecto, por el momento.

Con el fin de mitigar estos problemas, el modelo promovido por los Estados canadienses y colombianos y las propias empresas es la introducción de un código (volontario) de RSC. Dentro de este modelo, el Estado se retira del proceso de negociación entre las comunidades y las empresas, con la consecuencia de que, en teoría, las empresas mineras pueden entrar tras negociaciones directas caracterizadas por enormes desigualdades con respecto al conocimiento, acceso a la información y representación legal. También hay 
una falta de claridad en el establecimiento de representantes de la comunidad o de cómo manejar las divisiones en la comunidad, y los líderes son a menudo cooptados con la oferta de trabajo (Mining Watch Canada 2009; NorthSouth Institute, 2012; Рв I Colombia, 2011). Cabe destacar que un problema fundamental en el proceso es que las comunidades no cuentan con un derecho claro de veto. En el escenario más común no hay ningún proceso de consulta; en otros casos la consulta se realiza después de la concesión de títulos o, finalmente, los proyectos de desarrollo local prometidos en los acuerdos simplemente no se materializan. Las propuestas de códigos de RSC son voluntarias y no incorporan mecanismos de reclamación que podrían dar lugar a sanciones y reparaciones (North-South Institute, 2012). Como Glennie (2013) ha señalado acertadamente:

\footnotetext{
Si la acción voluntaria funcionara, podríamos esperar ver una gran cantidad de ejemplos en los que el RSC ha sido respetada o comunidades se han beneficiado de la invasión de la minería sin a) la necesidad de invocar la ley y $b$ ) largas luchas por la justicia de las comunidades en cuestión, con el apoyo nacional e internacional de la sociedad civil y medios de comunicación. Pero no hay nada, sólo las cuentas sin fin de las comunidades que pierden todo.
}

La evidencia sugiere abrumadoramente que las protecciones de la RSC sirven más como un escudo ideológico que como una política seria para los Estados o corporaciones.

\section{Conclusión}

Mientras que la economía política mundial ha sido caracterizada por el aumento en las tendencias hacia el «imperialismo extractivo», este trabajo ha analizado cómo estas dinámicas se han integrado en la trayectoria histórica 
de las relaciones de poder y las luchas de clase en el contexto muy particular de Colombia. Si el auge del capital extractivo en Colombia es un reflejo de las tendencias del capitalismo mundial hacia estrategias de «acumulación por desposesión», aquí hemos visto cómo esa dinámica debe ser entendida desde la perspectiva territorial de interacción de los procesos nacionales de lucha de clases y las relaciones de poder entre los bloques de élite con los procesos internacionales de acumulación de capital. El auge de la minería colombiana surgió en el contexto de la llegada al poder de un bloque mafioso de la élite rural durante la presidencia de Uribe, que se enfrentaba a una creciente presión tanto desde adentro, a través de las fricciones entre los sectores de la élite, y desde abajo, a través de la persistente amenaza de la guerrilla. En este contexto, el déficit fiscal creado por préstamos internacionales y los crecientes costos militares se fijó mediante la colocación de una apuesta desesperada por atraer a la inversión extranjera en la minería. El camino fue allanado para el extractivismo tanto en las reformas institucionales como en la creación de las condiciones «sobre el terreno» a través de la estrategia de despojo violento a manos de las fuerzas paramilitares patrocinadas por el Estado. Las actuales negociaciones de paz pueden reflejar un cambio en la política gubernamental hacia la creación de condiciones en el terreno para el capital extractivo a través de la estabilidad social y no la guerra. En este contexto ha surgido el plan nacional de desarrollo basado en el crecimiento económico impulsado por la extracción de recursos naturales o, en otras palabras, el proyecto de la acumulación por desposesión patrocinado por el Estado.

Con respecto a la cuestión de las fuerzas de resistencia que rodean el auge de la minería, en el caso de Colombia estos movimientos son mejor entendidos como el último capítulo en la larga trayectoria histórica de la lucha entre campesinos, indígenas y afrodescendientes, trabajadores y el capital junto con el Estado. Desde el escenario internacional, a la evolución de las tendencias de la acumulación de capital se agrega una nueva dinámica a esta trayectoria, pero sería un error concluir que estas luchas se entenderían mejor como movimientos que surjen contra la acumulación por desposesión. El uso 
de estrategias fraudulentas, engañosas y violentas de acumulación primitiva siempre ha desempeñado un papel importante en la generación de fuerzas de la resistencia. La reciente intensificación de las estrategias de las empresas multinacionales monopolistas ha traído una ola de costos sociales y ambientales, los cuales son pagados en gran medida por los trabajadores y las comunidades locales. A su vez, la reciente intensificación de estrategias ha impulsado la «locomotora» de la resistencia. Con la regeneración y reconfiguración de la lucha de clases en Colombia, estas fuerzas actualmente ofrecen la posibilidad de lograr alternativas estructurales al modelo de desarrollo dominante.

\section{Bibliografía}

ABColombia (2012), «Giving It Away: The Consequences of an Unsustainable Mining Policy in Colombia», en 〈http://www.christianaid.org.uk/ images/giving-it-away-colombia-mining-report.pdf〉.

(2011), «Returning Land to Colombia's Victims», en 〈http //www. abcolombia.org.uk/downloads/ReturningLandReportforweb.pdf $\rangle$.

Banco de la República (s/f), Series estadísticas, en 〈http://www.banrep. gov.co/series-estadisticas/see_s_externo».

Benson, Allison (2011), «La Guajira y El Cerrejón: Una historia de contrastes», Supuestos, en 〈http://revistasupuestos.uniandes.edu.co/?p=1517〉.

Brittain, James (2007), «La vacilante economía política de Uribe», Controversia, número 188.

CINEP (2012), «Minería, conflictos sociales y violación de DDHH», en 〈http:// www.cinep.org.co/index.php?option $=$ com_docman\&task=doc_details \&gid=263\&Itemid $=117 \&$ lang $=$ en $>$.

Contraloría General de la República (2011), «Estado de los Recursos Naturales y del Ambiente 2010-2011», en 〈http://186.116.129.19/c/document_library/get_file?\&folderId=21259911\&name $=$ DLFE-36069.pdf . Cuervo, Yohanna (2012), «Una aproximación a la megaminería en Colom- 
bia», Theomai, número 25, en 〈http://www.revista-theomai.unq.edu. ar/numero25/CuervoSotelo.pdf $>$.

Cumming, John (2004), «Greystar Resumes Exploration at Angostura», en 〈http://www.northernminer.com/issuesV2.aspx〉.

Departamento Administrativo Nacional de Estadistica (dane) (s/f), «Estadísticas nacionales» en 〈http://www.dane.gov.co/».

Departamento Nacional de Planeación (2010), «Bases Del Plan Nacional De Desarrollo 2010-2014», en 〈http://www.cna.gov.co/1741/ articles-311056_PlanNacionalDesarrollo.pdf.

Dinero (2008), «Futuro minero», Dinero.com, en 〈http://www.dinero. $\mathrm{com} / /$ caratula/edicion-impresa/articulo/futuro-minero/64081>.

El Espectador (2011), «Minería amenaza páramos», Elespectador.com, en 〈http://www.elespectador.com/impreso/politica/articulo-247071mineria-amenaza-paramos .

Fernández, Juan y Mario Valencia (2010), Libre comercio y minería en Colombia: El caso de la Anglogold Ashanti, ReCALCA, en «http://www.redge. org.pe/sites/default/files/TLC_mineria_colombia.pdf .

Fierro, Julio (2012), Políticas mineras en Colombia, Bogotá, Instituto Latinoamericano para una Sociedad y un Derecho Alternativos.

Fraser Institute (2010), «Survey of Mining Companies: 2009/2010», en 〈http://www.fraserinstitute.org/research-news/display.aspx?id=15953〉.

Fundación Friedrich Ebert Colombia (fescol) (2011), «Pobreza y desigualdad. Un balance de la información disponible», en 〈http://library.fes.de/pdf-files/bueros/kolumbien/08400.pdf.

GlenNie, Jonathan (2013), «Colombia's resistance to corporate mining excess has lessons for the world», The Guardian, en 〈http://www.guardian.co.uk/global-development/poverty-matters/2012/may/14/colombia-resistance-corporate-mining-excess .

Gordon, Todd y Jeffery R. Webber (2008), «Imperialism and Resistance: Canadian Mining Companies in Latin America», Third World Quarterly, volumen 29, número 1 . 
Harvey, David (2005), El nuevo imperialismo, New York, Oxford University Press.

Ismi, Asad (2012), «Profiting from Repression: Canadian Investment in and Trade with Colombia», Americas Update magazine, en 〈awww.asadismi. ws/colombiareport.html.

Leech, Garry (2004), «Plan Petroleum in Putumayo», Colombia Journal, en 〈http://colombiajournal.org/plan-petroleum-in-putumayo.htm〉. (2006), Crude Interventions: The United States, Oil and the New World (Dis) Order, Zed Books.

Ministerio de Defensa (2012), «Logros De La Política Integral De Seguridad y Defensa», en 〈http://www.mindefensa.gov.co/irj/go/km/docs/ Mindefensa/Documentos/descargas/estudios\%20sectoriales/info_estadistica/Logros_Sector_Defensa.pdf $\rangle$.

Ministerio de Minas y Energía (s/f), «Invierta en Colombia», en 〈http:// Www.cancilleria.gov.co/colombia/information/invest〉.

Mining Watch Canada (2009), Land and Conflict. Resource Extraction, Human Rights, and Corporate Social Responsibility: Canadian Companies in Colombia, Ottawa, Mining Watch Canada, en 〈http://www.interpares.ca/en/publications/pdf/Land_and_Conflict.pdf .

North-South Institute (2012), «Caught in the Crossfire: Indigenous Peoples, Black Communities and Extractives in Colombia», NorthSouth Institute, en 〈http://www.nsi-ins.ca/publications/caught-inthe-crossfire-indigenous-peoples-black-communities-and-extractives-in-colombia-2/ $>$.

O’Connor, Dermot y Juan Bohórquez (2010), «Neoliberal Transformation in Colombia's Goldfields: Development Strategy or Capitalist Imperialism?», LABOUR, Capital and Society, volumen 43, número 2.

Orduz, Natalia (2012), «Desviación del Río Ranchería, ¿`sí o no?», La Silla Vacía, en http://www.lasillavacia.com/historia/desviacion-del-riorancheria-si-o-no-35572 .

Pardo, Alvaro (2012), «Minería, Renta Minera y Tributación», Colombia Pun- 
to Medio, en http://www.colombiapuntomedio.com/Portals/0/NuestrosDocumentos/Miner\%C3\%ADa,\%20renta\%20minera\%20y\%20 tributaci\%C3\%B3n\%202.pdf〉.

Peace Brigades Colombia (рві) (2011), «Mining in Colombia: at what price?»

Projet Accompagnement Solidarité Colombie (pasc) (2012), «Targeting Canadian Profiteers of the War in Colombia», en 〈http //www. pasc.ca/sites/pasc.ca/files/u5/targetingCanadianWarProfiteer.pdf .

Petras, James (2000), «Geopolitics of Plan Colombia», Economic and Political Weekly, volumen xxxv, número 52-53.

Pulido, Alejo y Camilo Osorio (2011), «Las preguntas detrás de AngloGold Ashanti», Censat, en 〈http://www.censat.org/articulos/10030-noticia/10264-las-preguntas-detras-de-anglogold-ashanti>.

Ramírez, Francisco (2011), «Transnacionales y minería en páramos», CENSAT, en 〈Www.censat.org〉.

Richani, Nazhi (2010), «The Agrarian Rentier Political Economy», Latin American Research Review, volumen 47, número 2.

(2010), «Colombia: Predatory State and Rentier Political Economy», Labour, Capital and Socitey, volumen 43, número 2. (2005), «Multinational Corporations, Rentier Capitalism, and the War System in Colombia», Latin American Politics E Society, volumen 47, número 3.

Sequera, Vivian (2012), «Rebels step up attacks on Colombia energy targets», Yahoo! Finanzas, en 〈http://finance.yahoo.com/news/rebelsstep-attacks-colombia-energy-targets-181308106.html>.

La Silla Vacía (2013), «Así es la pobreza que rodea a las grandes mineras», en 〈http://www.lasillavacia.com/historia/asi-es-la-pobreza-que-rodea-las-grandes-mineras-41651>.

Stokes, Doug (2006), “Iron Fists in Iron Gloves”: The Political Economy of us Terrorocracy Promotion in Colombia», The British Journal of Politics E International Relations, volumen 8 , número 3. 
Superintendencia de Sociedades (2012), «Comportamiento del sector real de la economía», en 〈http://www.supersociedades.gov.co/imagenes/cominicaciones/INFORME_SECTOR_REAL_Ajustado.pdf).

Valencia, Mario (2012), «Por qué defender a la pequeña minería en Colombia?», Conalminercol, en 〈http://www.recalca.org.co/por-que-defender-a-la-pequena-mineria-en-colombia/ $/$.

VANGUardia (2012), «Agenda con las farc debe tener más ofertas que diálogo: líderes empresariales», Vanguardia.com, en 〈http://www.vanderbilt.edu/lapop/news/083112.Colombia-Vanguardia.pdf .

Veltmeyer, Henry (2013), «The Political Economy of Natural Resource Extraction: a New Model or Extractive Imperialism?», Canadian Journal of Development Studies/Revue Canadienne D'études Du Développement, volumen 34, número 1 .

Vicecontralor General de la República (2007), «El desplazamiento forzado de los colombianos y sus impactos patrimoniales», ponencia presentada en la coferencia «Territorio, Patrimonio y Desplazamiento», Bogotá, citado en S. Gutierrez, El displazamiento interno en Colombia, en 〈http:// www.colectivodeabogados.org/EL-DESPLAZAMIENTO-INTERNO-EN >.

Villamil, Edwin (2013), «Condiciones laborales de trabajadores mineroenergéticos», en 〈http://www.youtube.com/watch?v=cpx1ai1X8fE».

Ziвechi, Raúl (2012), «La paz del extractivismo en Colombia», La Jornada, en 〈http://www.jornada.unam.mx/2012/09/07/opinion/021a2pol».

Zúvíiga, Fernando (2010), «Regalías en el país de Simón El Bobito», en 〈http://www.razonpublica.com/index.php/econom-y-sociedad-temas-29/1151-regalias-en-el-pais-de-simon-el-bobito.html. . 